\title{
AVALIAÇÃO DA ADSORÇÃO DO CORANTE ISOLAN NHF-S (1-ISOPROPIL-3-METILPIRAZOL-5-DIMETILCARBAMATO) UTILIZANDO DIFERENTES ADSORVENTES
}

\author{
I. H. M. OLIVEIRA ${ }^{1}$, P. A. M. FREITAS ${ }^{1, *}$ \\ ${ }^{1}$ Instituto Mauá de Tecnologia, Departamento de Engenharia Química (EEM/CEUN-IMT) \\ *E-mail para contato: pantonio@maua.br
}

\begin{abstract}
RESUMO - Considerando o descarte de efluentes da indústria têxtil sem tratamento, estudos foram realizados a fim da eliminação deste contaminante, por meio da técnica de Extração em Fase Sólida (SPE). A adsorção do Isolan NHF-S em diferentes fases sólidas (carvão ativo, turfas orgânicas decomposta e fibrosa, sílica-gel e fibra de coco verde) foi efetuada utilizando a espectrofotometria UVVisível. A absortividade molar do corante, 3450,5 $\mathrm{L} \mathrm{mol}^{-1} \mathrm{~cm}^{-1}$, foi obtida com a elaboração de uma curva analítica. Constatou-se que para o processo adsortivo o carvão ativo e a turfa orgânica decomposta apresentaram resultados favoráveis, com adsorção de $0,643 \pm 0,008 \mathrm{~g} \mathrm{~g}^{-1}$ para o carvão ativo e $0,470 \pm 0,045 \mathrm{~g} \mathrm{~g}^{-1}$ para a turfa decomposta, ambos com absorbância lida de $580 \mathrm{~nm}$ e pH do corante 6,8 .
\end{abstract}

\section{INTRODUÇÃO}

Os corantes são muito difíceis de se decompor e os métodos convencionais, tais como a coagulação, a fotodegradação, a ozonização, embora amplamente utilizados, não são tão eficazes (Ho e Mckay, 1998).

No processo de tingimento têxtil estima-se que entre 10-15\% do corante é perdido no efluente, e se essa perda for descartada diretamente no meio ambiente, poderá gerar sérios problemas nos processos biológicos aquáticos fundamentais (Paschoal e Tremiliosi Filho, 2005). Muitos desses corantes que têm estruturas moleculares complexas aromáticas, também são tóxicos, cancerígenos, e representam uma séria ameaça para os organismos vivos.

Infelizmente, tratamentos de águas residuais convencionais são ineficazes na remoção de corantes e envolvem alto custo, formação de subprodutos perigosos, e exigências de energia elétrica intensiva. Os processos de adsorção fornecem resultados diferenciados, pois podem ser usados para remover diferentes tipos de materiais de coloração, proporcionando um tratamento atrativo (Freitas et al., 2007), especialmente quando adsorventes de baixo custo estão disponíveis. Diversos adsorventes podem ser utilizados para remoção de corante no efluente têxtil.

O foco deste trabalho se concentra no estudo do adsorvente mais apropriado para remoção do corante Isolan NHF-S do efluente têxtil. A Tabela 1 apresenta as propriedades do corante (1-Isopropil-3-metilpirazol-5-dimetilcarbamato). Os adsorventes estudados foram: carvão ativo, turfas decomposta e fibrosa, sílica-gel e fibra de coco verde seca e triturada. 
Tabela 1 - Propriedades do corante Isolan NHF-S

\begin{tabular}{|cc|}
\hline Massa molecular & $211,26 \mathrm{~g} \mathrm{~L}^{-1}$ \\
\hline Absortividade molar & $3450,5 \mathrm{~L} \mathrm{~mol}^{-1} \mathrm{~cm}^{-1}$ \\
\hline Caracterização & Corante direto \\
\hline Aplicação & Indústria têxtil \\
\hline $\begin{array}{c}\text { Estrutura } \\
\text { molecular e } \\
\text { microestrutura }\end{array}$
\end{tabular}

Segundo Westphalen et al., 2016, o carvão ativado é utilizado como adsorvente de contaminantes orgânicos hidrofóbicos presentes em baixas concentrações na água. A porosidade desenvolvida deste material, o torna um excelente adsorvente na indústria têxtil.

A turfa é um sedimento orgânico formado a partir da decomposição parcial de material vegetal em um ambiente úmido, ácido e de baixa oxigenação (Petroni e Pires, 1999). A complexação de metais pesados presentes em ambientes aquáticos torna a turfa, tanto decomposta quanto fibrosa, um ótimo adsorvente.

Airoldi e Farias, 1999, estudaram o uso da sílica gel como agente sequestrante para metais e verificaram as diversas possibilidades de aplicação analítica das matrizes inorgânicas quimicamente modificadas desse adsorvente. Tal aplicação é importantíssima na indústria têxtil, onde o efluente descartado apresenta uma enorme gama de resíduos metálicos.

Um outro adsorvente muito utilizado na indústria é a fibra de coco verde. A demanda crescente por fibras de coco se dá em razão do interesse por produtos ecologicamente corretos, por ser proveniente de uma fonte renovável, biodegradável e de baixo custo (Mattos et al., 2012) e por suas características oferecerem diversas possibilidades de utilização como adsorvente.

\section{OBJETIVOS}

O presente trabalho consiste em avaliar o comportamento de diferentes fases sólidas frente à adsorção do corante Isolan NHF-S.

Têm-se como objetivos específicos:

a) ativação dos diferentes adsorventes: fibra de coco verde, turfa decomposta, turfa fibrosa, carvão ativo e sílica-gel;

b) estudo das características espectrais do Isolan NHF-S em pH 6,8;

c) estudo do comportamento do sistema Isolan NHF-S/fase sólida em bancada por espectrofotometria UV-Vis e comparação das massas de corante adsorvidas nas fases sólidas. 


\section{MATERIAL E MÉTODOS}

Considerando que o Isolan NHF-S, apresenta absorção molecular, a espectrofotometria foi utilizada para estudar a adsorção na superfície dos adsorventes. Tal determinação tem como fundamento a comparação entre as concentrações do corante, presentes em solução, antes e após o contato com a fase sólida.

As turfas fibrosa e decomposta, a fibra de coco verde, o carvão ativo e a sílica-gel foram utilizados como adsorventes, para a remoção do corante Isolan NHF-S.

As fases sólidas foram devidamente pesadas com mesma proporção em balança analítica Ohaus Adventurer. A lavagem das fases sólidas ocorreram em funis de separação de vidro Squibb com torneira de PTFE e rolha de polipropileno utilizando-se água deionizada com sistema de purificação Mili-Q. Após a lavagem, as fases sólidas foram secas em estufa a $56^{\circ} \mathrm{C}$ durante 48 horas e armazenadas em frascos de polietileno devidamente tampados e rotulados.

Soluções estoque de Isolan NHF-S do fabricante DyStar Group ${ }^{\circledR}$ foram preparadas pela solubilização de aproximadamente $0,1 \mathrm{~g}$ do corante com água deionizada em sistema de purificação Mili-Q, a temperatura de $25^{\circ} \mathrm{C}$. Em seguida, as soluções foram armazenadas em frasco âmbar e em ambiente escuro para evitar degradação.

A partir da solução estoque $\left(5,01 \times 10^{-3} \mathrm{~mol} \mathrm{~L}^{-1}\right)$, foram preparadas $10 \mathrm{~mL}$ de soluções em diferentes concentrações $(0,503 ; 0,401 ; 0,299 ; 1,02 ; 2,03 ; 3,07) \times 10^{-4} \mathrm{~mol} \mathrm{~L}^{-1}$, com água deionizada, e construiu-se a curva analítica em pH 6,8.

Os espectros de absorção do corante foram obtidos, utilizando-se um espectrofotômetro Shimadzu UV-2600 e cubetas de quartzo Hellman com caminho óptico de 1,00 cm, objetivando a determinação do comprimento de onda máximo do corante em pH 6,8.

As microestruturas dos adsorventes foram gentilmente reproduzidas pela Anacom Científica em alta resolução pelo Microscópio Eletrônico de Varredura (MEV), Phenon Word.

Certa massa de cada adsorvente foi pesada em balança analítica da Ohaus Adventurer, em tubos de polietileno Falcon ${ }^{\circledR}$ com capacidade de $10 \mathrm{~mL}$, e colocado em contato com a solução do corante, $2,52 \times 10^{-4} \mathrm{~mol} \mathrm{~L}^{-1}$, $\mathrm{pH} 6,8$. O sistema permaneceu sob agitação orbital constante de $300 \mathrm{rpm}$ a $25^{\circ} \mathrm{C}$ utilizando um Shaker de bancada Maconi MA140CFT.

Após dez minutos de contato, a solução remanescente foi colocada em uma cubeta de quartzo para a realização da leitura de absorbância, em duplicata. A quantidade de corante adsorvida na superfície de cada adsorvente foi calculada a partir da diferença entre a concentração inicial da solução $\left(\mathrm{C}_{\mathrm{o}}\right)$ e a obtida no sobrenadante, após a interação do sistema sólido-líquido. 


\section{RESULTADOS}

A relação entre absorbância e a concentração do corante permitiu a observação de uma faixa de linearidade (Lei de Beer), em $580 \mathrm{~nm}$, comprimento de onda no qual a absorbância do corante foi máxima. A faixa de concentração estudada $\left(C_{0}\right)$, foi de $(0,503$ a 3,07$) \times 10^{-4}$ mol L ${ }^{-1}$. Os parâmetros encontrados foram: coeficiente linear da reta $(0,0002)$ e o coeficiente angular, que corresponde à absortividade molar do Isolan NHF-S $\left(3450,5 \mathrm{~L} \mathrm{~mol}^{-1} \mathrm{~cm}^{-1}\right) . \mathrm{O}$ coeficiente de correlação $\left(\mathrm{R}^{2}\right)$ obtido foi de 0,9984 .

As Figuras 1 e 2 apresentam os espectros de absorção do corante Isolan NHF-S em diferentes concentrações e a curva analítica, em pH 6,8 e $580 \mathrm{~nm}$.

As microestruturas de cada adsorvente utilizado obtidas por Microscopia Eletrônica de Varredura estão apresentadas na Figura 3.

Figura 1 - Espectros de absorção do corante em pH 6,8, $\mathrm{C}_{\mathrm{o}}=$ (I) $2,99 \times 10^{-5}$; (II) $4,01 \times 10^{-5}$; (III) $5,03 \times 10^{-5}$; (IV) $1,02 \times 10^{-4}$; (V) $2,03 \times 10^{-4}$; (VI) $3,07 \times 10^{-4}\left(\mathrm{~mol} \mathrm{~L}^{-1}\right)$

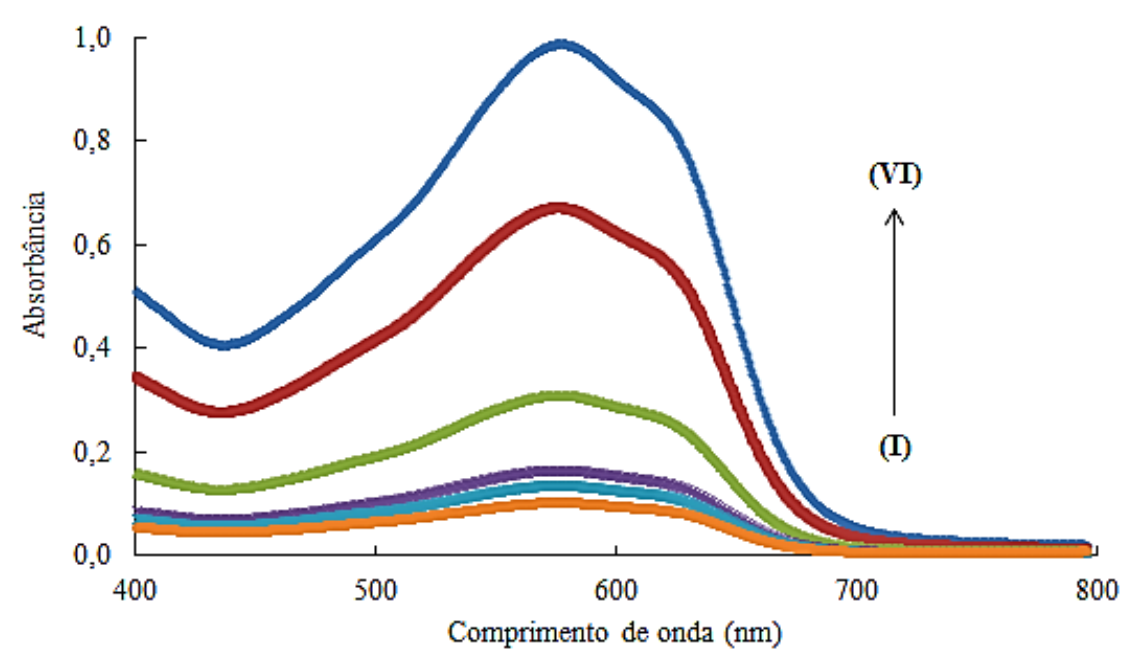

Figura 2 - Curva analítica do Isolan NHF-S em pH 6,8, $580 \mathrm{~nm}$

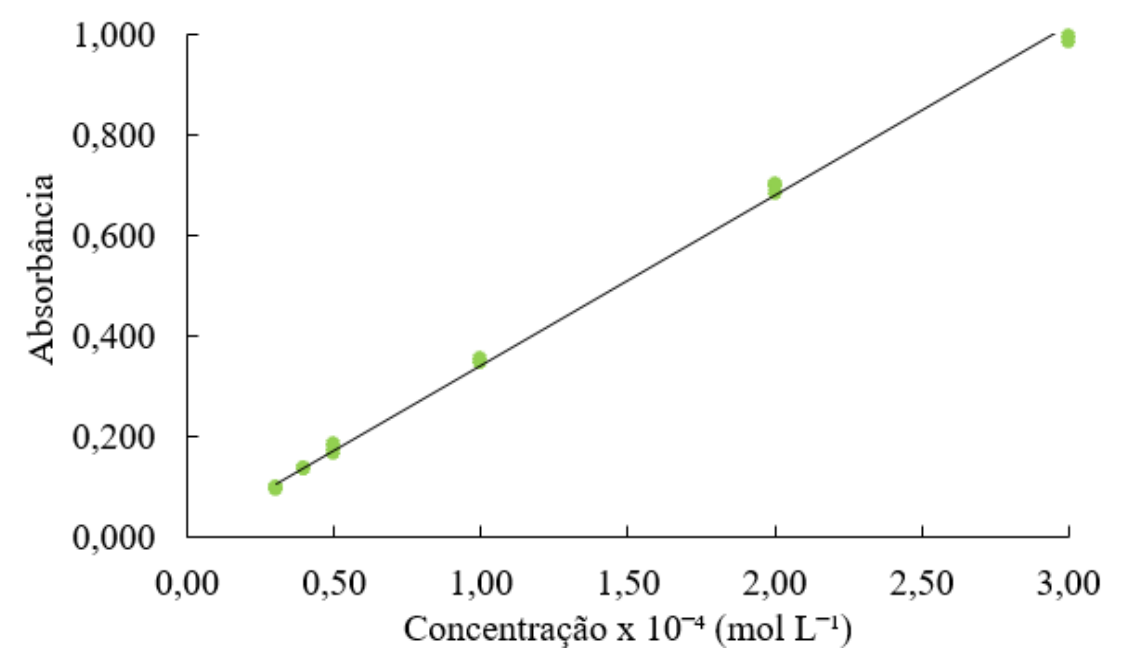


Figura 3 - Microestruturas dos adsorventes estudados. (I) Carvão ativo; (II) Fibra de coco verde triturada; (III) Sílica-gel; (IV) Turfa decomposta; (V) Turfa fibrosa

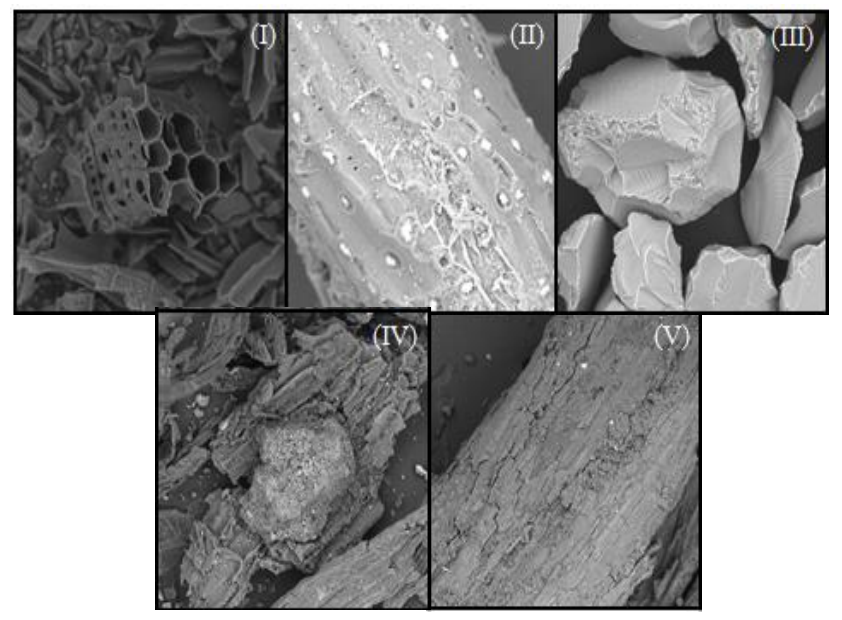

Observaram-se diferentes formas e tamanhos de poros e sabe-se que a adsorção do corante está relacionada a isso. A Tabela 2 apresenta os valores de massa do corante adsorvida em cada fase sólida e a porcentagem de adsorção.

Tabela 2 - Massa de corante adsorvida em cada fase sólida, com solução de $2,52 \times 10^{-4}$ mol L ${ }^{-1}$, em $\mathrm{pH}$ 6,8, 10 minutos de contato

\begin{tabular}{|ccc|}
\hline Adsorvente & mads $/$ mfase sólida & \% de adsorção \\
\hline Carvão ativo & $0,643 \pm 0,008$ & $72,0 \%$ \\
Turfa decomposta & $0,470 \pm 0,045$ & $50,5 \%$ \\
Turfa fibrosa & $0,347 \pm 0,024$ & $36,4 \%$ \\
Sílica-gel & $0,375 \pm 0,021$ & $40,3 \%$ \\
Fibra de coco verde & $0,320 \pm 0,032$ & $31,7 \%$ \\
\hline
\end{tabular}

O carvão ativo apresenta microestrutura com muitos poros, por isso, a adsorção do corante Isolan NHF-S foi tão eficiente nesta fase sólida já que o poder penetrativo é facilitado pela presença de poros. Sua estrutura química apresenta basicamente carbono, o que lhe dá uma alta capacidade de adsorção à estrutura polar do corante Isolan NHF-S.

A fibra de coco verde utilizada não apresentou resultados que justificassem o seu uso como adsorvente do corante estudado. Pode-se observar que sua microestrutura apresenta poucos poros ou pontos de adsorção do corante à sua estrutura, semelhantemente à turfa fibrosa. Já na turfa decomposta, ranhuras em sua microestrutura pode ser observada. Recorrendo-se à estrutura química da turfa, percebe-se grupos polares que apresentam bastante afinidade com grupos metil do corante. Além disso, a microestrutura em forma de ranhuras da turfa decomposta se acopla à microestrutura oval e aberta do corante Isolan NHFS, explicando a boa adsorção apresentada frente aos demais adsorventes estudados.

Nascimento e Stela, 2015 diz que a produção do carvão ativado é relativamente cara devido ao alto consumo de energia em sua fabricação, além do uso de matérias-primas caras. 
Assim, como alternativa ao carvão ativo, a turfa decomposta apresenta elevado potencial para a adsorção de efluentes do corante Isolan NHF-S da indústria têxtil, por se tratar de um bioadsorvente encontrado nos depósitos turfáceos da plataforma continental do Brasil (Côrrea et al, 2014) com a maior capacidade adsortiva dentre os bioadsorventes estudados.

\section{CONCLUSÃO}

Foi possível utilizar a técnica espectrofotométrica no UV-Visível para o estudo da adsorção do corante Isolan NHF-S nos adsorventes propostos, uma vez que o adsorbato apresenta absorção na região ultravioleta do espectro $(580 \mathrm{~nm})$. O carvão ativo melhor adsorveu o corante $\left(6.43 \times 10^{-1} \mathrm{~g} \mathrm{~g}^{-1}\right)$ e a turfa decomposta apresentou uma favorável adsorção $\left(4,70 \times 10^{-1} \mathrm{~g} \mathrm{~g}^{-1}\right)$ quando comparada aos demais adsorventes estudados. Considerando a adsorção e as propriedades físicas do adsorvente, a turfa é um material apropriado em futuras aplicações analíticas

\section{REFERÊNCIAS}

CÔRREA, I.C.S.; WESCHENFELDER, J.; TOLDO JR., E.E.J; BAITELLI, T.; SANTOS, C.B. Peat on the continental shelf of Southern Brazil. Comunicações geológicas, v.101, p. 721-724, 2014.

FREITAS, P. A de. M.; IHA, K.; SUARÉZ-IHA, M. E.V. Kinetic modeling of adsorption of di-2pyridylketone salicyloylhudrazone on sílica gel. Journal of Colloid and Interface Science v.307, 2007.

HO, Y. S.; MCKAY, G. Sorption of dye from aqueous solution by peat. Chem. Eng. Journal, v.70, p.115-124, 1998.

MATTOS, A.L.A; ROSA, M de. F.; CRISÓSTOMO, L.A; BEZERRA, F.C; CORREIA, D.; VERAS, L.G.C. Beneficiamento da casca de coco verde. Embrapa, São Paulo, 2012.

NASCIMENTO, I.J.N; STELA, É.R. Produção de carvão ativado a partir de moinha de carvão vegetal. Encontro Internacional de produção científica UniCesumar, p.4-8, 2015.

PASCHOAL, F.M.M; TREMILIOSI-FILHO, G. Application of the electroflocculation technology for the recovery of índigo blue from industrial effluents. Química Nova, v.28, São Paulo, 2005.

PETRONI, S.L.G; PIRES, M.A.F. Adsorção de zinco e cádmo em colunas de turfa. Química Nova, v.23, p.477-481, 1999.

UCHOA, P.K.S.; SILVA, D.C.; GOUVEIA, S.T. O uso da fibra de coco para adsorção, separação e especiação de cromo III e IV. Congresso brasileiro de química, 2007.

WESTPHALEN, A.P.C; CORÇÃO, G.; BENETTI, A.D. Utilização do carvão ativado biológico para o tratamento de água para consumo humano. Eng Sanit Ambient, v.21, p.425436, 2016. 